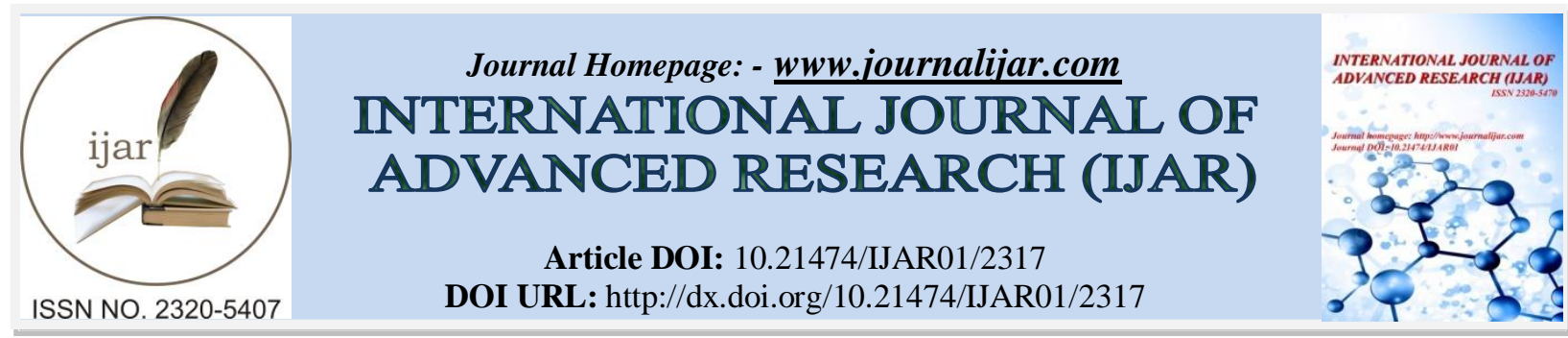

RESEARCH ARTICLE

\title{
ASSESSMENT OF WOMEN 'KNOWLEDGE REGARDING COMPLIANCE AND SAFETY OF ORAL CONTRACEPTIVE PILLS.
}

Fatimah Qasim Jaber Ahmadi, Samar Marei Ali Alqahtani, Rawan Mohammed Ahmad Asiri and Norah Saad Alfrhan Alshehri.

Medical interns, Faculty of Medicine, King Khalid University, Abha, Saudi Arabia

\section{Manuscript Info}

Manuscript History

Received: 29 September 2016

Final Accepted: 30 October 2016

Published: November 2016

Key words:-

Oral contraceptive pills; side effects;

knowledge; unintended pregnancy.

\section{Abstract}

Background:- Most of Saudi women are using OCPs as a method of contraception.Failure rates of less than one percent have been reported among women who use OCPs effectively, with rates as high as nine percent in those who do not use pills consistently or correctly.

Objectives:- to study the compliance with as well as knowledge regarding OCP among women attending King Faisal armed forces hospital at Khamis Mushait and Family and community department clinics at Ahad Rufaidah.

Subjects and methods:- Cross-sectional study design was carried out among married Saudi women, aged over 18 years attending King Faisal armed forces hospital at Khamis Mushait and Family and community department clinics at Ahad Rufaidah, Southern Region, Saudi Arabia during November, 2016 and using OCPs for a period of more than 6 months.Simple random technique was applied to select all eligible women to complete a questionnaire to assess their Knowledge on adherence and safety of the oral contraceptive pill. A selfadministered Arabic-questionnaire will be used for collection of data.

Results:- Three hundreds women participated in the study. The age of $45.3 \%$ of them ranged between 30 and 39 years. Slightly less than half of them $(47.3 \%)$ had Bachelor degree or above whereas $6.7 \%$ were less than intermediate school educated. About two-thirds of the participants $(65 \%)$ understood that they needed totake an extra pill if they forgot to take one in less than 12 hours. However, only $14 \%$ were aware that theyneeded to take an extra pill and use extra protection forthe next 7 days if they missed taking their OCP for morethan 12 hours. Majority of the participants were unawareof the correct action to take if they had experienceddiarrhea for more than 12 hours (93.7\%), or vomited within 2hours of taking an OCP (88.7\%). Less than one-fifth of the participants could recognize that smoking affects contraceptive use. However, majority of them $(81.7 \%)$ have read the package insert inside OCPs packages. Overall, sufficient knowledge was reported among $22.7 \%$ of women. The commonest reported OCPs side effects were weight gain $(56 \%)$, nausea $(36.3 \%)$, tender breast (35.7\%), and facial acne pimples and body hair (26.7\%). Abnormal vaginal bleeding was significantly associated with years of OCPs use 
as it was more reported among those used OCPs foe less than one year compared with longer duration, $\mathrm{p}=0.031$.

Conclusion:- Majority of Saudi women using OCPs have insufficient knowledge of its correct use regarding missingpills, diarrhea and vomiting, and poor awareness of the impacts of smoking while using OCPs.Proper counseling and counseling on correct use of OCPs are recommended to raise their knowledge to limit unintended pregnancies and consequentlyimprovetheir health

Copy Right, IJAR, 2016,. All rights reserved.

\section{Introduction:-}

Oral contraceptive pills (OCPs) are the most widely used method of contraception worldwide because of their accessibility and reversibility. ${ }^{1}$ Unfortunately, their efficacy is limited by problems related to compliance with prescribed regimens, which is in turn related to knowledge about correct usage and the occurrence of adverse events. $^{2}$

Most oral contraceptives (the pill) contain a combination of female hormones, estrogen and progestin. This combination reduces the risk of pregnancy by preventing ovulation, keeping the mucus in the cervix thick and impenetrable to sperm and keeping the lining of the uterus thin. ${ }^{3}$

Failure rates of less than one percent have been reported among women who use OCPs effectively, with rates as high as nine percent in those who do not use pills consistently or correctly. ${ }^{4,5}$

Most of Saudi women are using OCPs as a method of contraception. ${ }^{6}$ In the United State, eleven million women in the age group 15-44 years used contraceptive pills. ${ }^{7}$ However, one million unintended pregnancies are associated annually with misuse or discontinuation of OCP. ${ }^{8}$ International studies suggest that up to $47 \%$ of women do not fully compliant with OCP with $22 \%$ missing two or more OCPs per cycle. ${ }^{9}$

Unintended pregnancy is an important public health issue in both developed and developing countries because of its negative association with social and health outcomes for both mothers and children. ${ }^{10}$

Missing or forgetting to take the OCP is reported as one of the main reasons for seeking emergency contraception. ${ }^{11}$ In women that rely on OCP for contraception. Poor compliance with OCP may therefore be a primary cause of unintended pregnancy in those that rely on this method of contraception, which is an important concern for public health. ${ }^{12}$

Possible side effects of the OCPs are nausea, breast tenderness, bloating, and mood changes, which typically improve within two to three months without treatment. ${ }^{13}$ Additionally, breakthrough bleeding or spotting is particularly common during the first few months of taking oral contraceptives. This almost always resolves without any treatment within two to three months. Forgetting a pill can also cause breakthrough bleeding. ${ }^{14}$

This study aimedto study the compliance with as well as knowledge regarding OCP among women attendingKing Faisal armed forces hospital at Khamis Mushait and Family and community department clinics at Ahad Rufaidah.

\section{Subjects and methods:-}

Cross-sectional study design wascarried out among married Saudi women, aged over 18 years attendingKing Faisal armed forces hospital at Khamis Mushait and Family and community department clinics at Ahad Rufaidah, Southern Region, Saudi Arabia during November, 2016 and using OCPs for a period of more than 6 months.

The sample size was calculated according to Bartlett et al. (2001) ${ }^{15}$ Thus minimal sample size was 278 women. At selected clinics in King Faisal armed forces hospital at Khamis Mushait and Family and community department clinics at Ahad Rufaidah. Simple random technique was applied to select all eligible women to complete a questionnaire to assess their Knowledge on adherence and safety of the oral contraceptive pill. Women who used 
oral contraceptive for indication other than contraception (dysmenorrhea, irregular cycles, acne) and those who had taken OCPs for less than or equal to 6 months were excluded.

A self-administered Arabic-questionnaire was used for collection of data. It has been previously used in another Saudi study. ${ }^{16}$ It has 18 items. They covered patient demographic data includingage, educational level, occupation, number of children, patient history regarding oral contraceptives, andknowledge of their correct use. In addition, commonside effects experienced with oral contraceptive use wereassessed.

Approval from the Research and Ethics Committee at King Khalid University in Abha was obtained. The researcher took permission also from the participant women after explaining the purpose of the study to all of them. A verbal consent was obtained from each participant prior to studyconduction.

Data were entered to a personal computer and will be analyzed by using Statistical Package for the Social sciences (SPSS) program version 23. Regarding knowledge questions, a score of "1" was assigned to correct answer whereas a score of "0" was assigned to wrong answers. Total knowledge score and percentages were computed. Those scored $50 \%$ and over were considered as having "sufficient knowledge" whereas those scored below $50 \%$ were considered as having "insufficient knowledge". Chi-squaretest was used for the association between categorical variables. A pvalue of less than 0.05 was adopted for statistical significance.

\section{Results:-}

Three hundreds women participated in the study. Table 1 presents their demographic characteristics. The age of 45.3\% of them ranged between 30 and 39 years. Slightly less than half of them (47.3\%) had Bachelor degree or above whereas $6.7 \%$ were less than intermediate school educated. Almost two thirds of them $(63.4 \%)$ were house wives. Number of children exceeded 4 among $26.7 \%$ of them and $22.3 \%$ reported taking of OCPs for at least four years.

Table 1:- Demographic characteristics of the participants $(n=300)$.

\begin{tabular}{|l|l|l|l|}
\hline & & Frequency & Percentage \\
\hline Age (years) & $<30$ & 101 & 33.7 \\
& $30-39$ & 136 & 45.3 \\
& $\geq 40$ & 63 & 21.0 \\
\hline Educational level & -Intermediate school & 20 & 6.7 \\
& Intermediate school & 34 & 11.3 \\
& High school & 80 & 26.7 \\
& Diploma & 24 & 8.0 \\
& Bachelor and above & 142 & 47.3 \\
\hline Occupation & Student & 16 & 5.3 \\
& Housewife & 190 & 63.4 \\
& Employed; Health care professional & 7 & 2.3 \\
& Employed; others & 87 & 29.0 \\
\hline Number of children & None & 7 & 2.3 \\
& $1-2$ & 116 & 38.7 \\
& $3-4$ & 97 & 32.3 \\
& $>4$ & 80 & 26.7 \\
\hline Years of contraceptive taken & $<1$ year & 35 & 11.7 \\
& 1 year & 77 & 25.7 \\
& 2 years & 47 & 15.7 \\
& 3 years & 74 & 24.7 \\
& $\geq 4$ years & 67 & 22.3 \\
\hline
\end{tabular}

Table 2 summarizes the knowledge of the correct utilization of the OCPs wasevaluated by the responses to 6 questions. About two-thirds of the participants $(65 \%)$ understood that they needed totake an extra pill if they forgot to take one in less than 12 hours. However, only $14 \%$ were aware that theyneeded to take an extra pill and use extra protection for 
Table 2:- Responses of the participants to knowledge questions about the proper oral contraceptives use.

\begin{tabular}{|l|l|l|}
\hline Questions & Correct responses & No. $(\%)$ \\
\hline $\begin{array}{l}\text { If you forgot to take your pill less than } \\
12 \text { hours ago, what do you do? }\end{array}$ & $\begin{array}{l}\text { Take it as soon as you remember, even if } \\
\text { that meant taking pills in the same day. }\end{array}$ & $195(65.0)$ \\
\hline $\begin{array}{l}\text { If you forgot to take your pill more than } \\
12 \text { hours ago, what do you do? }\end{array}$ & $\begin{array}{l}\text { Take it as soon as you as you remember, } \\
\text { even if that meant taking 2 pills in the same } \\
\text { day plus use extra protection for the next } 7 \\
\text { days. }\end{array}$ & $42.0)$ \\
\hline $\begin{array}{l}\text { If you vomit within 2 hours of taking } \\
\text { the tablet, what do you do? }\end{array}$ & Take an extra pill. & $34(11.3)$ \\
\hline $\begin{array}{l}\text { If you have diarrhoea for more than 12 } \\
\text { hours after the pill was taken, what } \\
\text { should you do? }\end{array}$ & $\begin{array}{l}\text { Take another tablet once diarrhea is resolved } \\
\text { plus Use other method of protection for the } \\
\text { next 7 days. }\end{array}$ & $19(6.3)$ \\
\hline $\begin{array}{l}\text { Do you think smoking affects } \\
\text { contraceptive use? }\end{array}$ & Yes & $55(18.3)$ \\
\hline \begin{tabular}{l} 
Have you read the package insert? \\
\hline
\end{tabular} & Yes & $245(81.7)$ \\
\hline
\end{tabular}

The next 7 days if they missed taking their OCP for morethan 12 hours. Majority of the participants were unawareof the correct action to take if they had experienceddiarrhea for more than 12 hours (93.7\%), or vomited within 2 hours of taking an OCP (88.7\%). Less than one-fifth of the participants could recognize that smoking affects contraceptive use. However, majority of them $(81.7 \%)$ have read the package insert inside OCPs packages. Overall, sufficient knowledge was reported among $22.7 \%$ of women as illustrated in figure 1. None of the studied demographic factors (age, occupation, educational level, number of children and duration of OCPs use) was significantly associated with women` knowledge regarding proper OCPs use. Table 3

Table 3:- Factors associated with knowledge of proper oral contraceptives use among women.

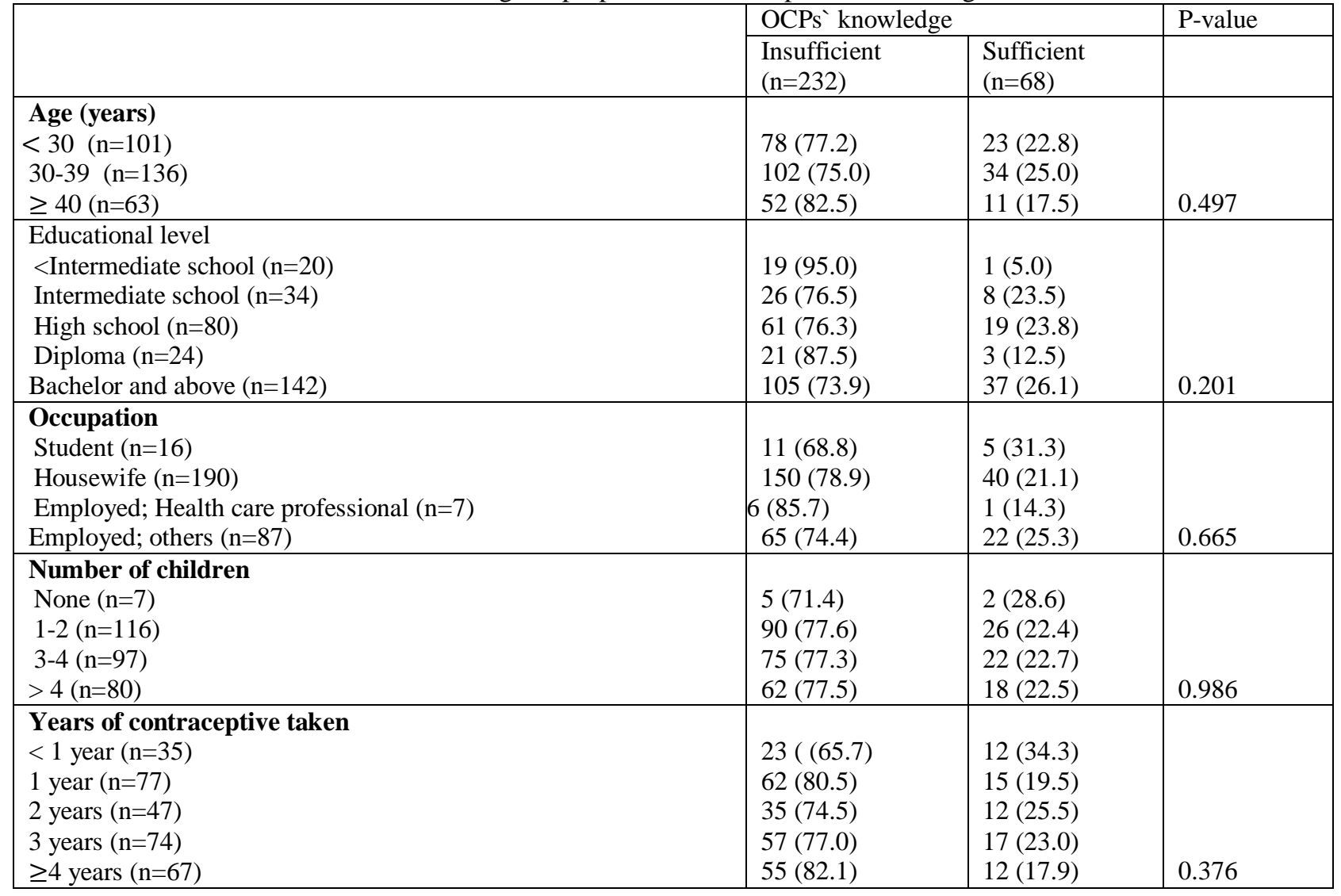




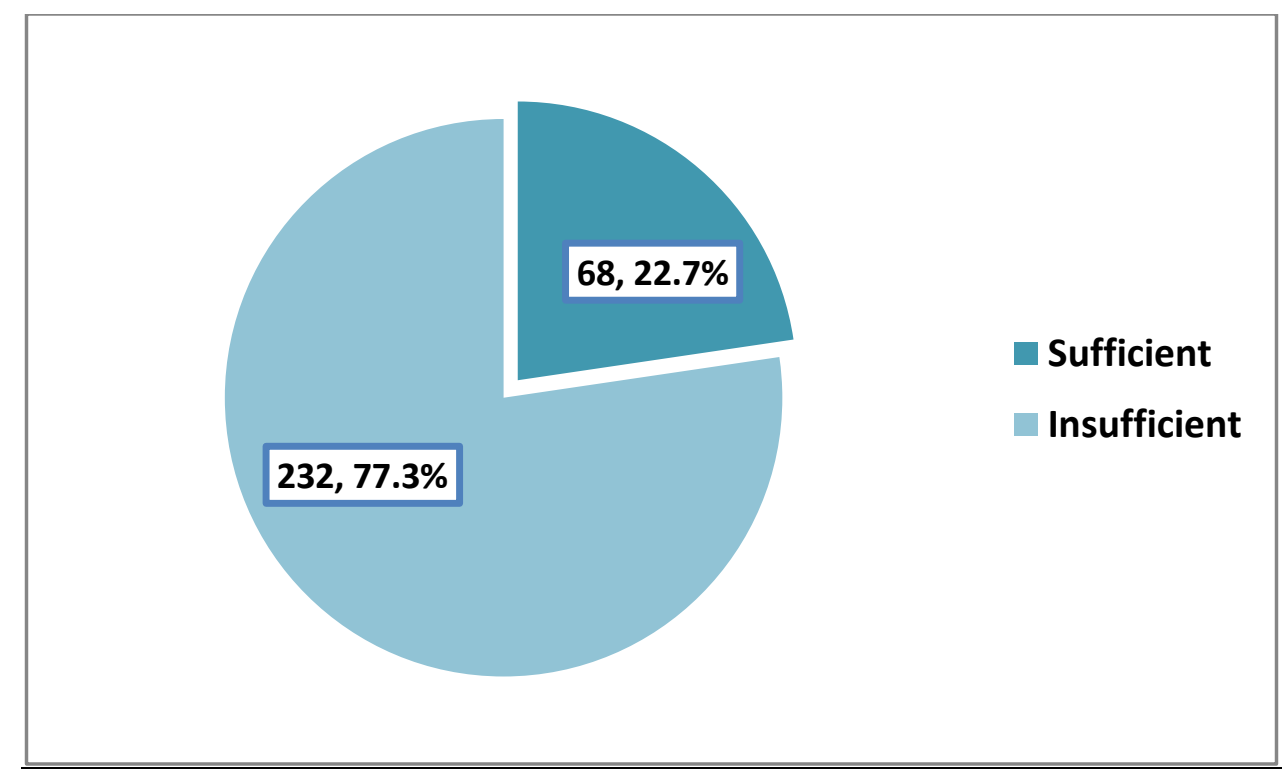

Figure 1:- Knowledge level of the participants about proper oral contraceptives use.

Regarding OCPs` side effects, figure 2 shows that the commonest reported were weight gain (56\%), nausea (36.3\%), tender breast (35.7\%), and facial acne pimples and body hair (26.7\%).

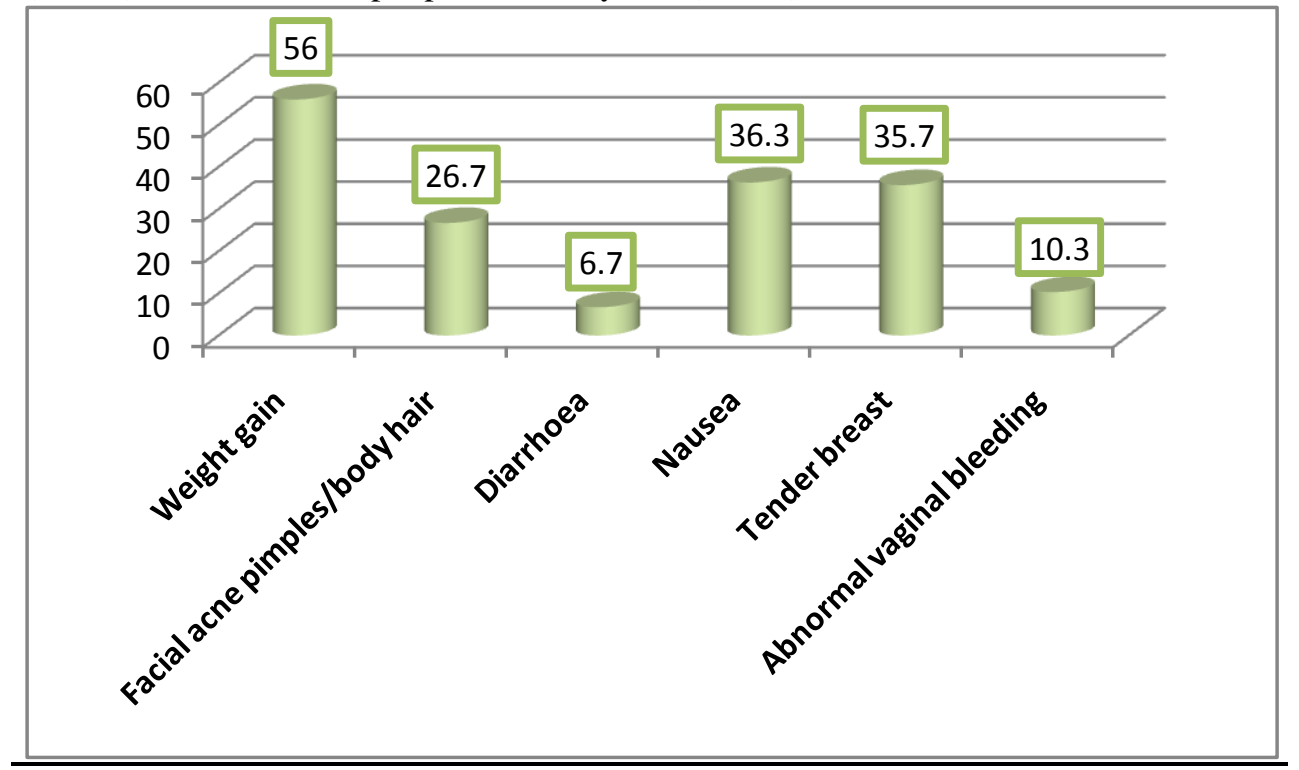

Figure 2:- Side effects of oral contraceptive pills

Studying the demographic factors associated with OCPs`side effects yielded only significant association between weight gain and woman`s age as $68.3 \%$ of those aged 40 or more years were more likely to report weight gain compared to those aged between 30 and 39 years $(47.8 \%)$. The difference was statistically significant, $\mathrm{p}=0.018$. Also, the was a significant impact of woman`s occupation on weight gain as $71.4 \%$ of health care professionals compared to $48.1 \%$ of house wives reported weight gain, $\mathrm{p}=0.004$. Abnormal vaginal bleeding was significantly associated with years of OCPs use as it was more reported among those used OCPs foe less than one year compared with longer duration, $\mathrm{p}=0.031$. Other associations between demographic characteristics of women and OCPs side effects were not statistically significant. Table 4 
Table 4:- Significant association between women`s demographic characteristics and oral contraceptive pills` side effects.

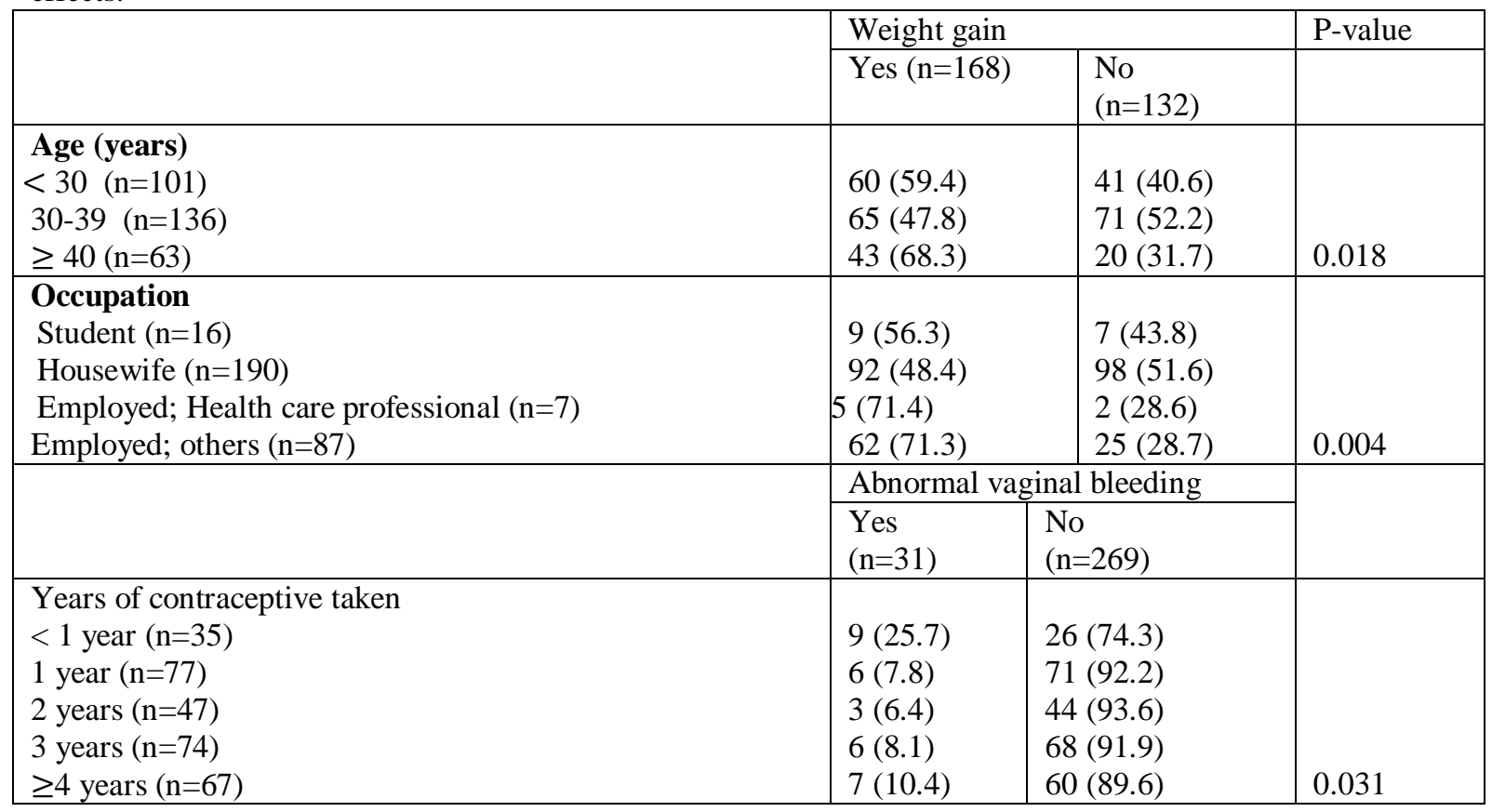

\section{Discussion:-}

The contraception use can have a positive influence on better child spacing, child care, improvement of health of children, and is considered as an effective preventive measure against maternal and child morbidity ${ }^{17}$ In the current study, theknowledge of Saudi women regarding OCPs use was investigated. Overall, knowledge regarding missing pills, vomiting, anddiarrhea among Saudi women in this study were insufficient. This finding is in accordance with other Saudi studies carried out in Riyadh ${ }_{20}^{16} \mathrm{Al}$-Khobar, ${ }^{18}$ and Qassim Region. ${ }_{21}^{19}$ In India, $11.2 \%$ of the studypopulation were aware of contraception. Other studies in Pakistan and in rural southern Nigeria revealed a higher value of awareness of contraception; $81 \%$ and $92.2 \%$ respectively. This insufficient knowledge and awareness could be potential causes of unintendedpregnancy. ${ }^{23}$ In the United States, each year more than ten million women intake the OCP to prevent pregnancy; three hundred thousands of those women become pregnant each yearduring a month in which they have been taking thepill. ${ }^{24}$

In the current study, $81.7 \%$ of the Saudi women claimed that they had read the package insert so it appearsthat this information source is well accepted. However,despite reading the package inserts their knowledgeon the proper OCPs use was mostly insufficient. The same has been reported in another Saudi study carried out in Riyadh. ${ }^{16}$ For mostwomen, the OCP package insertis the sole source of information, which explains their risks and benefits, side effects, and what to do whenthey have missed taking pills, Yet, these specific points of informationin the inserts might be difficult to find and understood The information varies betweenmanufacturers, with the text of most package insertswritten at a tenth to twelfth grade reading level, wellabove the sixth grade reading level usually recommendedfor health education materials by the Federal DrugAssociation. ${ }^{25}$

Therefore, we recommended developing asimpler, more understandable, an accurate and specific patient package insert for inclusion in all packs of oralcontraceptives to increasethe clarity of information across oralcontraceptive brands. Also, providing patientswith a simple booklet and reading material on properuse of OCP can enhance their knowledge of OCPuse. ${ }^{26}$ In addition tothese, reinforcement ofthe key messages by verbal counseling from physicians, nurses or pharmacistson OCP use is a good way to improve patient knowledge. ${ }^{27}$

The current study showed that although higher educated women had more sufficient knowledge regarding OCPs use compared to less educated women, however, this was not significant statistically. In a study carried out in South Africa, also education level of women was not significantly associated with proper OCPs use. ${ }^{28}$ It had been 
documented that educated women aremore likely to be aware of the health services, including family planning services thatare available, have more confidence inusing them than less educated women. ${ }^{15}$ Additionally, more educated women have more work opportunities, which reflects their tendency to postpone starting a family to complete their career. ${ }^{15}$ In Middle East countries, including KSA, higher educated women tend to limit familysize to have more time to take care of their children. ${ }^{29}$

Years of contraception usewas not significantly associated with a better knowledge of compliancein the present study contrary to what has been reported in another Saudi study where prolonged use of OCPs was associated with better knowledge. ${ }^{15}$

Smoking while on the pill of more than fifteen cigarettes per day at age35 or above will increase the risk ofstroke, and is considered a contraindication. ${ }^{30}$ However, most participants in the present study couldn't recognize that smoking affects contraceptive use.This finding is of relative importance in Saudi Arabia due tothe increasing incidence of smoking among females. ${ }^{31}$

Some studies have reported that at least half of OCPs` users discontinue the pill within the first yearbecause of fears, side effects, and lack of knowledge. ${ }^{32,33}$ Twenty percent of the annual unintended pregnanciesin the United States are linked to discontinuation of OCPs mainly because of its unpleasant side effects. ${ }^{34}$ In the current study, $56 \%$ reported weight gain as a side effect,although clinical trials have failed to establish arelationship between OCP use and weight gain. ${ }^{35}, 36$ The second most commonly reported side effect wasnausea $(36.3 \%)$, which is higher than those reported in theliterature ${ }^{37}$ In addition, tender breast (35.7\%), facial acne pimples and body hair (26.7\%) were reported amongst OCPs`side effects in the present study. Quite similar findings have been documented in another Saudi study. ${ }^{16}$

Among limitations of the current study, it waslimited to one institution,therefore, although our hospital treats allof the Saudi population in Khamis Mushait, the study population may not be fully representative ofSaudi women using the OCPs.

In conclusion, the study showed that mostSaudi women taking the OCP have insufficient knowledge ofits correct use regarding missing pills, vomiting, diarrhea and poor awareness of the effects of smoking with OCPuse. Therefore, proper education and counseling on correct OCPuse are recommended to improve their knowledge to protect their health and limit unintended pregnancies.

\section{References:-}

1. Allen K. Contraception-common issues and practical suggestions. AustFam Physician. 2012;41(10):770-772.

2. Iftikhar R, Aba Al Khail BA. Knowledge about missed contraceptive pills among married women at King Abdulaziz University Hospital. Patient Preference and Adherence 2015;9: 401-411

3. Petitti DB. Clinical practice. Combination estrogen-progestin oral contraceptives. N Engl J Med 2003; 349:1443.

4. Trussell J. Contraceptive failure in the United States. Contraception. 2011;83(5):397-404.

5. Marnach ML, Long ME, Casey PM. Current issues in contraception. Mayo Clin Proc. 2013;88(3):295-299.

6. Al-Turki HA. Contraception: attitudes and experiences of Saudi Arabian women. Health Care Women Int. 2011;32(2):134-9.

7. Mosher WD, Martinez GM, Chandra A, Abma JC, Willson SJ. Use of contraception and use of family planning services in the United States: 1982-2002. Adv Data. 2004 ;(350):1-36.

8. Rosenberg MJ, Waugh MS, Long S. Unintended pregnancies and use, misuse and discontinuation of oral contraceptives. J Reprod Med 1995; 40: 355-360.

9. Rosenberg MJ, Waugh MS, Burnhill MS: Compliance, counseling and satisfaction with oral contraceptives: a prospective evaluation. Fam Plann Perspect 1998, 30(2):89-92. 104.

10. El-Zanaty F, Way A. Egypt Demographic and Health Survey, 2005. Cairo, Egypt: Ministry of Health and Population, National Population Council, El-Zanaty and Associates, and Macro International 2006.

11. Lader D. Opinions survey report No. 41 Contraception and Sexual Health, 2008/09. London: Office for National Statistics; 2009.

12. Cleand J, Conde-Agudelo A, Peterson H, Ross J, Tsui A: Contraception and health. Lancet 2012, 380(9837):149-156. 
13. Rosenberg MJ, Meyers A, Roy V. Efficacy, cycle control, and side effects of low- and lower-dose oral contraceptives: a randomized trial of 20 micrograms and 35 micrograms estrogen preparations. Contraception 1999; 60:321.

14. Bachmann G, Korner P. Bleeding patterns associated with oral contraceptive use: a review of the literature. Contraception 2007; 76:182.

15. Bartlett JE, Kotrlik JW, Higgins CC. Organizational Research. Determining Appropriate Sample Size in Survey Research. Information Technology, Learning, and Performance Journal 2001; 19(1):43-50.

16. Al-Shaikh GK, Mayet AY, Alshaikh MK, Hamad AF, Mahmoud MA, Aljadhey HS. Knowledge on adherence and safety of the oral contraceptive pill in Saudi women. Saudi Med J. 2012 Jun;33(6):665-70.

17. Utoo BT, Mutihir TJ, Utoo PM. Knowledge, attitude and practice of family planning methods among women attending antenatal clinic in Jos, North-central Nigeria. Niger J Med.2010; 19(2):214-8.

18. Al-Mansour R, Sabra AA, Hafez AS. Contraception: Knowledge, Attitude and Practice with Special Emphasis on Contraceptive Pills among Saudi Women at Al-Khobar City, Eastern Saudi Arabia. The Egyptian Journal of Community Medicine 2012 April; 30 (2): 1-13

19. Al Sheeha M. Awareness and use of contraceptives among saudi women attending primary care centers in Alqassim, saudiarabia. Int J Health Sci (Qassim). 2010;4(1):11-21.

20. Takkar N, Goel P, Saha PK, Dua D. Contraceptive practices and awareness of emergency contraception in educated working women . Indian J Med Sci. 2005;59:143-9.

21. Mustafa R, Afreen U, Hashmi HA. Contraceptive knowledge, attitude and practice among rural women. J Coll Physicians Surg Pak. 2008; 18(9):542-5.

22. Omo-Aghoja LO, Omo-Aghoja VW, Aghoja COO, konofua FE, Aghedo O, Umueri C. Factors associated with the knowledge, practice and perception of contraception in rural southern Nigeria. Ghana Med J. 2009;43(3):115-21.

23. Rosenberg MJ, Waugh MS. Oral contraceptive discontinuation: a prospective evaluation of frequency and reasons. Am J ObstetGynecol 1998; 179: 577-582.

24. Chandra A, Martinez GM, Mosher WD, Abma JC, Jones J.Fertility, family planning, and reproductive health of U.S.women: data from the 2002 National Survey of Family Growth.Vital Health Stat 2005; 23: 1-160.

25. Doak CC. Doak LG, Root JH, editors. Teaching patients withlow literacy skills. 2nd ed. Philadelphia (PA): J. B. Lippincott; 1996.

26. Newell S. Writing effective pamphlets: a basic guide, preparedfor Hunter Centre for Health Advancement. Newcastle (NSW): Southern Cross University; 1996.

27. Gazmararian JA, Parker RM, Baker DW. Reading skills andfamily planning knowledge and practices in a lowincomemanaged-care population. Obstet Gynecol 1999; 93: 239-244

28. Davis TC, Fredrickson DD, Potter L, Brouillette R, BocchiniAC, Williams MV, et al. Patient understanding and use of oralcontraceptive pills in a southern public health family planningclinic. South Med J 2006; 99: $713-718$.

29. Rashed H, Osman M, Roudi-Fahimi F, editors. Marriage in theArab World. Washington (DC): Population Reference Bureau; 2005.

30. Black A, Francoeur D, Rowe T, Collins J, Miller D, Brown T, etal. SOGC clinical practice guidelines: Canadian contraceptionconsensus. J ObstetGynaecol Can 2004; 26: 219-296.

31. Al Ghobain MO, Al Moamary MS, Al Shehri SN, Al-HajjajMS. Prevalence and characteristics of cigarette smoking among16 to 18 years old boys and girls in Saudi Arabia. Ann Thorac Med 2011; 6: 137-140.

32. Fu H, Darroch JE, Haas T, Ranjit N. Contraceptive failurerates: new estimates from the 1995 National Survey of FamilyGrowth. Fam Plann Perspect 1999; 31: 56-63.

33. Rosenberg MJ, Waugh MS, Burnhill MS. Compliance, counseling and satisfaction with oral contraceptives: aprospective evaluation. Fam Plann Perspect 1998; 30: 89-92.

34. Rosenberg MJ, Waugh MS, Long S. Unintended pregnanciesand use, misuse and discontinuation of oral contraceptives. J Reprod Med 1995; 40: 355-360.

35. Coney P, Washenik K, Langley RG, DiGiovanna JJ, Harrison DD. Weight change and adverse event incidence with a lowdoseoral contraceptive: two randomized, placebo-controlledtrials. Contraception 2001; 63: $297-302$.

36. Endrikat J, Hite R, Bannemerschult R, Gerlinger C, SchmidtW. Multicenter, comparative study of cycle control, efficacyand tolerability of two low-dose oral contraceptives containing20 microgethinylestradiol/100 microglevonorgestrel and20 microgethinylestradiol/500 micrognorethisterone. Contraception 2001; 64: 10.

37. Rosenberg MJ, Waugh MS. Oral contraceptive discontinuation:a prospective evaluation of frequency and reasons. Am J ObstetGynecol 1998; 179: 577-582. 